\title{
Does Positive Feedback of Social Impact Motivate Prosocial Behavior? A Field Experiment with Blood Donors*
}

\author{
Lorenz Goette $\quad$ Egon Tripodi
}

First version: October 2, 2019

This version: May 2, 2020

\begin{abstract}
Positive feedback about the outcome of volunteers' prosocial actions is often thought to help motivate continued volunteers' engagement. In the context of blood donations, various collection systems have begun to provide blood donors feedback on successful utilization of their blood donation. An experiment conducted by the main NGO that supports the collection of blood in Italy studies how such feedback affects subsequent blood donations. From a sample of over 8'000 blood donors, we find that providing feedback of successful utilization decreases donations. Though surprising, these results are consistent with theoretical models in which individuals engage in prosocial behavior to sustain a positive self-image: feedback about the outcome of a recent donation can act as reminders that boost self-image and reduce the need for re-engaging soon in prosocial activities. Interestingly for policy, we also show that combining the feedback with an explicit request to sign up for a new donation can eliminate, but not overturn, the negative effect of the feedback.
\end{abstract}

Keywords: Prosocial behavior, blood donations, moral licensing, field experiment.

Goette: University of Bonn, Institute for Applied Microeconomics, Adenauerallee 24-42, 53113 Bonn; lorenz.goette@uni-bonn.de. Tripodi: European University Institute, Department of Economics, Via delle Fontanelle 18, 50014 San Domenico di Fiesole; egon.tripodi@eui.eu. We acknowledge research funding from the Deutsche Forschungsgemeinschaft through grants \#411047502, CRC TR 224 (Project B07), and Germany's Excellence Strategy (EXC 2126/1 390838866). This study could have not been possible without the full cooperation of AVIS Toscana. We extend our gratitude to Adelmo Agnolucci, Filomena Autieri, Luciano Franchi, and Donata Marangio at AVIS Toscana, and Simona Carli at CRS for their collaboration and data sharing. Maximilian Blesch, Benedikt Kauf, Julian König, Carina Lenze, and Valerie Stottuth have provided excellent research assistance. All errors remain our own. 


\section{Introduction}

Individuals care that their civic engagement generates positive externalities and is recognized. Providing information about impact and recognition is often a low marginal cost activity. As a result, across various domains simple gestures like saying thank you (Panagopoulos, 2011), publicizing civic actions (Gerber et al. (2008); Lacetera and Macis (2010)), or reminding people of their identity in the community (Bryan et al. (2011)) can be very effective at promoting socially desirable behaviors.

In this paper we examine the effect of informing individuals of the positive impact of their own actions in the case of blood donations. This type of intervention resembles a policy that has recently been implemented at national scale in countries such as Australia, Ireland, the United Kingdom, and Sweden. The costs of implementing the policy are low: there are fixed costs to set up the information system that can be substantial, but once a system is in place sending the marginal feedback has virtually no cost. Much less is known about the benefits of such policy, as rigorous evaluation is not yet available. This paper fills this gap, providing evidence to inform blood collection systems. This evidence can have broader implications that extend to other settings of prosocial behavior and civic engagement.

We evaluate the results of an experimental intervention conducted by the main NGO that supports the collection of blood in Italy. This study involves a sample of 8'591 regular blood donors in Italy. All donors in the study receive a formal email communication from the organization. This communication has an experimental component that is varied in a $2 \times 2$ experimental design. At the time of the intervention, for all donors in the sample, the last blood donation was successfully utilized. The main variation of interest that is implemented is whether or not the email contains a feedback of successful utilization of their latest blood donation. On top of that, the organization also cross-randomized whether the email contains an invitation for the donor to schedule early an appointment for the next donation. This was done to benchmark the effect of the positive feedback to an explicit request to donate, and can be helpful to investigate a potential way in which the positive feedback could eventually be made more 
effective by including an explicit request to donate. ${ }^{1}$

Our main result is that providing a positive feedback about the utilization of the last donation decreases donations over the study period by $6.9 \%$. This effect is also $7 \%$ of a standard deviation in the outcome of interest, a significant magnitude both statistically and quantitatively. We also find that asking donors explicitly to sign up early for their next donation has no significant effect on donations, and combining the positive feedback to the explicit sign-up request can undo the negative feedback effects, but not sufficiently so to deliver significantly more donations than in the control treatment.

While the null effect of asking to schedule an early appointment is not surprising in this context, because we are asking donors to make an appointment possibly too long before they become eligible to give blood again, the findings for the effects of positive feedback provide an illustration of how well meaning interventions designed to provide accountability and satisfaction to donors can backfire.

These results indicate that the effects of positive feedback of the social impact of individual actions are neither comparable to other forms of expression of gratitude, which are typically found to be positive from both empirical evidence and theory (Chaudhry and Loewenstein, 2019), nor are they comparable to standard reminders to contribute, which are also typically found to have positive effects (e.g. Huck and Rasul (2010); Sonntag and Zizzo (2015); Bruhin et al. (2020)).

The negative effects of positive feedback are consistent with a literature in psychology and economics in which prosocial behavior is at least partly motivated by a human desire to maintain a positive self-concept. Numerous laboratory experiments in social psychology (e.g. Monin and Miller (2001); Sachdeva et al. (2009)) illustrate that individuals tend to behave less morally when they receive positive reminders of their morality (moral licensing), and behave more morally when they receive negative reminders of their morality (moral cleansing). These tendencies have been explained through formal models of belief-dependent utility (Bénabou and Tirole, 2011; Bénabou et al., 2018). In such frameworks, agents care to see themselves as moral individuals and have imperfect memory to remember the kind of person they are and their past

\footnotetext{
${ }^{1}$ The policies commonly employed in the various countries previously mentioned feature a positive feedback without any explicit invitation to donate.
} 
behavior. Positive feedback can act as a reminder of past good actions and substitutes the need to immediately again engage in prosocial behavior. Prominent alternative explanations, such as selective recruitment efforts and location specific shocks, are ruled out by an experimental design that randomizes treatment assignment at the individual level while keeping the managers of donations recruitment blind to what treatment each donor receives. We also show that the negative effect of positive feedback is not due to substitution of blood donations with the donation of other blood components.

The rest of the paper is structured as follows: Section 2 describes the experimental design and procedures, Section 3 discusses the results, and Section 4 concludes.

\section{Experimental Design}

The study was conducted at the Tuscan chapter of the Associazione Volontari Italiani del Sangue (AVIS). ${ }^{2}$ The experiment that we advised AVIS Toscana to conduct was designed to satisfy their interest in identifying the benefits of implementing a popular nudge that is being used by blood collecting organizations in various countries, including Australia, Ireland, the UK, and Sweden. The nudge consists of informing donors of the impact of their donations as soon as they are utilized. ${ }^{3}$ An example of the feedback employed by the blood collection unit UK National Health Service if provided in Figure A1.

For a comprehensive evaluation of the policy the experiment compares how four different types of communications affect subsequent donation behavior. The main

\footnotetext{
${ }^{2}$ Blood collection in Tuscany is conducted at multiple hospitals and health facilities. However, the volunteers who do donate blood are typically affiliated with an association of blood donors. AVIS is the largest association of blood donors in the country, with regional branches in each of the 20 Italian regions. Blood donors are affiliated to one of about 160 local sub-branches of AVIS Toscana. Each subbranch manages independently recruitment of and repeated interaction with affiliates to maintain an active pool of blood donors. AVIS Toscana manages a centralized database of donations and contact details of the sub-branches' affiliates. To conduct this study, this database was integrated to records from the regional administration on utilization of the blood units.

${ }^{3}$ Though different collection systems implement different means of communication, and slightly different contents. The common feature across the different contexts is that donors are informed that their donation made on a certain date was either utilized or dispatched to a particular health facility. Partly due to privacy concerns of the recipient, messages sent to the donors typically lacks specificity about what the blood donation was used for.
} 
Feedback treatment of this study features a baseline communication plus a positive feedback regarding the utilization of the last unit of blood donated by the volunteer. This treatment is meant to provide both accountability and good feelings to the donors for their generosity, by letting donors know that their recent donation was successfully utilized.

In a pure Control treatment, volunteers receive only the baseline communication. This clean control treatment serves to identify the effect of specific email contents net of the effects that receiving an official communication in itself can have. This also overcomes common methodological issues of studies that in order to study inter-temporal effects in prosociality remind individuals of either their moral or immoral past actions (donut designs in the terminology of the review from Mullen and Monin (2016)).

Figure 1 illustrates what the email to donors in the Feedback treatment looked like. The contents of all communications are modular: the first four paragraphs of this email are common to all treatments, the fifth paragraph only features in the Feedback and the Feedback \& Appointment treatments. The Appointment and Feedback + Appointment treatments include a paragraph marked by a calendar icon that states: "As you know we are always in need of blood and plasma. Call our friends from AVIS subbranch_name (subbranch_phone_number) to set an appointment and come visit us soon for your next donation!". The rest of the email body is common to all treatments. ${ }^{4}$

In an additional Appointment treatment, used to benchmark the feedback effects, donors were encouraged to make an early appointment for their next donation. Finally, a Feedback $\mathcal{E}$ Appointment treatment, combines the content of the Feedback and Appointment to investigate the complementarities of eliciting an early appointment for the next donation while providing a positive feedback regarding the immediate past donation.

\footnotetext{
${ }^{4}$ All original contents of the experimental communications are provided in Appendix B.
} 


\section{QWIS GRS}

Ciao Egon,

We are working with the Centro Regionale Sangue to improve the information we are able to provide regarding the outcome of your donations.

You will soon have online access through a private account to the results of routine tests following each donation. We are also considering other systems to keep donors informed of the use of their donations.

If you have a suggestion regarding information you would like to receive, you may email us at informazioni@avistoscana.it. We will take into consideration all suggestions that we receive.

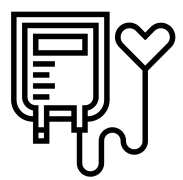

We are happy to inform you that your donation from May 9 has since been used!

Kind regards,

Adelmo Agnolucci

President, AVIS Toscana

Simona Carli

Director, Centro Regionale Sangue

To stay up to date with our initiatives, moments, and special thanks from recipients of blood and plasma donations follow Avis RegionaleToscana either on our website or Facebook.

Figure 1: Email Sent to Donors in the Feedback Treatment (Translated from Italian)

\subsection{Procedures}

All communications are personalized to capture the donor's first name, the date of their last donation for which feedback is being provided, the name of the sub-branch of the organization to which the donor is affiliated and its phone number dedicated for scheduling appointments to donate. Emails are sent from an institutional email address of AVIS Toscana using a Python script. ${ }^{5}$ The study is conducted in four waves in July, August, September, and October 2018. Each wave entails a blast of emails that is spread out over 5 business days and about 2'000 donors. These donors are the ones who have provided an email address to AVIS, have donated blood in a time frame that ranges between 3 and 7 weeks prior to the email blast, and whose donation

\footnotetext{
${ }^{5}$ The organization used various tools to determine the spam score of the content of every treatment. Including the logos on top of the email ensured identical spam score across all treatments, ruling out that treatment effects can be confounded by differential email delivery rates.
} 
was successfully utilized (for e.g. transfusions, and blood fractioning). Inclusion in an earlier wave automatically excludes a donor from being included in a subsequent wave.

Randomization into one of the four treatments is conducted at the individual level. This has two main benefits. First, by keeping the organization blind to which donor receives which treatment we can rule out that treatment effects are driven by differential recruitment efforts. Second, individual assignment greatly improves power over clustered treatment assignment, therefore we are able to detect smaller treatment effects with greater precision.

Notice that all communications are presented to donors as a joint initiative of AVIS Toscana together with the regional blood service. This has two main advantages: (i) the official aspect of these communications make it more likely that donors pay attention to the content of the emails sent; (ii) because the intervention was just another campaign that the organization conducted to encourage its base of volunteers to donate, this study falls in the category of what Harrison and List (2004) call "natural field experiments", which are largely believed to attenuate concerns for experimenter demand and Hawthorn effects.

In consultation with AVIS, we decided to evaluate the effects of the intervention on blood donations that were made in a seven months window following the latest blood donation that determined each subject's inclusion in the study. This time window was chosen to allow all donors to have at least one month to donate blood from the day they become legally eligible to donate again. ${ }^{6}$

\footnotetext{
${ }^{6}$ In Italy, women are only allowed to donate every six months, and men every three months. This means that for women we observe exactly one month worth of donations from when they become eligible to make another blood donation, and for men we observe exactly four months worth of donations. For both women and men, we also observe other types of donations, for components of blood that can be donated more frequently. In 2018, the donations of Tuscan AVIS donors are represented for $74.26 \%$ by blood donations and for $22.54 \%$ by plasma donations. All other components of blood together represent just $3.19 \%$ of the total collection, and are excluded from our analyses.
} 
Table 1: Demographics, Donation Behavior, and Engagement with the Experiment (Means and Standard Errors of the Means in Parentheses)

\begin{tabular}{|c|c|c|c|c|c|c|c|}
\hline & \multirow[b]{2}{*}{ Full sample } & \multirow[b]{2}{*}{ Study sample } & \multicolumn{4}{|c|}{ By treatment } & \multirow[b]{2}{*}{$\mathrm{p}$-value } \\
\hline & & & Control & Feedback & Appointment & $\begin{array}{l}\text { Feedback \& } \\
\text { Appointment }\end{array}$ & \\
\hline \multicolumn{8}{|c|}{ (a) Measured before treatment } \\
\hline \multirow[t]{2}{*}{ Female } & 0.265 & 0.261 & 0.255 & 0.270 & 0.269 & 0.247 & 0.248 \\
\hline & $(0.003)$ & $(0.005)$ & $(0.009)$ & $(0.009)$ & $(0.010)$ & $(0.009)$ & \\
\hline \multirow[t]{2}{*}{ Age } & 45.175 & 44.142 & 43.764 & 44.100 & 44.090 & 44.623 & 0.129 \\
\hline & $(0.084)$ & $(0.130)$ & $(0.262)$ & $(0.255)$ & $(0.257)$ & $(0.266)$ & \\
\hline \multirow[t]{2}{*}{ Past blood donations } & 1.202 & 1.225 & 1.222 & 1.226 & 1.219 & 1.232 & 0.941 \\
\hline & $(0.006)$ & $(0.010)$ & $(0.020)$ & $(0.020)$ & $(0.020)$ & $(0.020)$ & \\
\hline \multirow[t]{2}{*}{ Past plasma donations } & 0.265 & 0.265 & 0.292 & 0.255 & 0.242 & 0.27 & 0.200 \\
\hline & $(0.006)$ & $(0.009)$ & $(0.020)$ & $(0.018)$ & $(0.018)$ & $(0.018)$ & \\
\hline \multicolumn{8}{|c|}{ (b) Measured after treatment } \\
\hline \multirow[t]{2}{*}{ Blood donations over study period } & 0.585 & 0.588 & 0.605 & 0.563 & 0.585 & 0.600 & 0.044 \\
\hline & $(0.004)$ & $(0.006)$ & $(0.013)$ & $(0.013)$ & $(0.013)$ & $(0.013)$ & \\
\hline \multirow[t]{2}{*}{ Plasma donations over study period } & 0.158 & 0.157 & 0.173 & 0.159 & 0.144 & 0.152 & 0.416 \\
\hline & $(0.004)$ & $(0.006)$ & $(0.013)$ & $(0.012)$ & $(0.011)$ & $(0.011)$ & \\
\hline \multirow[t]{2}{*}{ Opened treatment email } & & 0.563 & 0.562 & 0.558 & 0.575 & 0.559 & 0.646 \\
\hline & & $(0.005)$ & $(0.011)$ & $(0.011)$ & $(0.011)$ & $(0.011)$ & \\
\hline \multirow[t]{2}{*}{ Treatment email views } & & 1.603 & 1.352 & 1.621 & 1.694 & 1.745 & 0.347 \\
\hline & & $(0.048)$ & $(0.046)$ & $(0.068)$ & $(0.153)$ & $(0.077)$ & \\
\hline Observations & 21225 & 8591 & 2121 & 2197 & 2178 & 2095 & \\
\hline
\end{tabular}

Note: Past blood (plasma) donations is the average number of blood (plasma) donations in the 12 months prior to the latest blood donation that qualified donors for being included in the study. Blood (plasma) donations over study period is the average number of donations over a period of seven months from the date of the blood donation that qualified donors for being included in the study. Opened treatment email is a binary indicator for whether the email sent to the donor for this study was open. Often such email is read multiple times: Treatment email views captures the number of views. The last column provides the p-value from a one-way ANOVA on ranks (Kruskal-Wallis) test comparing the four treatment groups.

Table 1 illustrates the observable characteristics of donors included in the analysis and the outcome measures. Women in our sample are under-represented because of differential legal restriction on the frequency of blood donations. In a year, donors in the study sample make on average 1.225 blood donations and 0.265 plasma donations in addition to the blood donation that qualifies them to take part in the study. In comparison, the larger population of donors who have made a blood donation in the weeks that determined participation in the study but could not participate due to lack of fulfillment of other eligibility requirements appears very similar on observable characteristics, with very small differences: on average, they are 1 year older and past blood donations are about $2 \%$ smaller than the study sample. The vast of majority of donors from the full sample that are not included in the study sample are excluded 
because they do not provide an email address to the organization. The comparison between the first two columns of Table 1 shows that donors providing an email address are fairly representative of the broader population of active donors. In fact, selection on observable characteristics introduced by the selection criteria is minor, and denote that the treatment effects identified in the study are likely to hold in a broader setting. Pre-treatment observable characteristics were all adequately balanced from the randomization procedure. The opening rates of treatment emails is encouragingly high and very similar across treatments. This rules out that differences in donation behavior can be attributed by differential email delivery rates across treatments.

\section{Results}

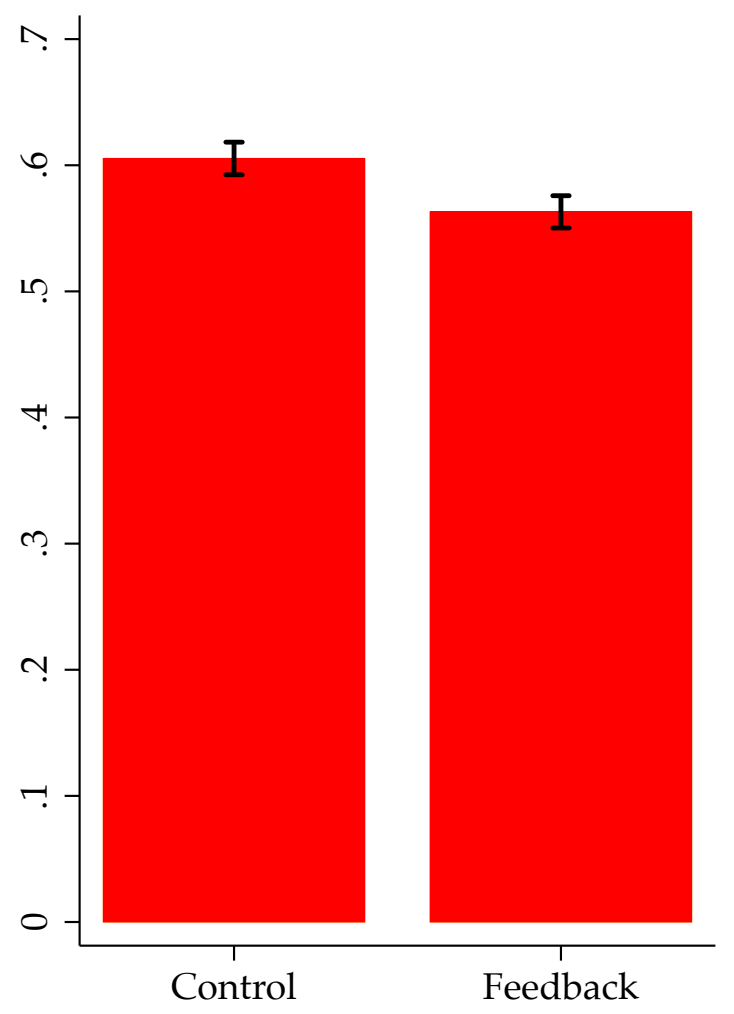

Figure 2: Blood Donations in Study Period, Control versus Feedback Treatments

The main result of this paper is presented in Figure 2. Providing donors with a positive feedback about the utilization of their donations reduces the average number of donations that donors make in the seven months of the study period. The negative ef- 
fects are large in magnitude: In the Control group donors on average give blood 0.605 times over the study period, in comparison, every 100 donors, 4.2 donations are lost when the positive feedback is provided.

Table 2: Ordinary Least Squares Regression Treatment Effects

\begin{tabular}{|c|c|c|c|c|c|c|c|c|c|}
\hline & \multicolumn{9}{|c|}{ Blood donations over study period } \\
\hline & \multicolumn{3}{|c|}{ Study sample } & \multicolumn{2}{|c|}{ by gender } & \multicolumn{2}{|c|}{ by past donations } & \multicolumn{2}{|c|}{ by timing email sent } \\
\hline & & & & \multirow{2}{*}{$\begin{array}{c}\text { Female } \\
(4)\end{array}$} & \multirow{2}{*}{$\begin{array}{c}\text { Male } \\
(5)\end{array}$} & \multirow{2}{*}{$\begin{array}{c}\text { Zero } \\
(6)\end{array}$} & \multirow{2}{*}{$\begin{array}{c}\text { One + } \\
(7)\end{array}$} & \multirow{2}{*}{$\begin{array}{c}\text { Early } \\
(8)\end{array}$} & \multirow{2}{*}{$\begin{array}{l}\text { Late } \\
\text { (9) }\end{array}$} \\
\hline & (1) & (2) & (3) & & & & & & \\
\hline & & & & Base & ine: Contrc & group & & & \\
\hline \multirow[t]{2}{*}{ Feedback } & $-0.042^{* *}$ & $-0.040^{* * *}$ & $-0.040^{* * *}$ & -0.028 & $-0.045^{* *}$ & -0.018 & $-0.051^{* * *}$ & $-0.054^{* *}$ & -0.024 \\
\hline & $(0.018)$ & $(0.015)$ & $(0.015)$ & $(0.034)$ & $(0.017)$ & $(0.032)$ & $(0.016)$ & $(0.023)$ & $(0.020)$ \\
\hline \multirow[t]{2}{*}{ Appointment } & -0.020 & -0.017 & -0.016 & -0.015 & -0.017 & 0.024 & -0.030 & -0.033 & 0.002 \\
\hline & $(0.023)$ & $(0.019)$ & $(0.019)$ & $(0.033)$ & $(0.019)$ & $(0.035)$ & $(0.020)$ & $(0.026)$ & $(0.027)$ \\
\hline \multirow[t]{2}{*}{ Feedback $\times$ Appointment } & $0.057^{* *}$ & $0.046^{*}$ & $0.045^{*}$ & 0.058 & $0.042^{*}$ & 0.023 & $0.056^{*}$ & $0.065^{* *}$ & 0.024 \\
\hline & $(0.027)$ & $(0.025)$ & $(0.024)$ & $(0.051)$ & $(0.024)$ & $(0.047)$ & $(0.028)$ & $(0.031)$ & $(0.029)$ \\
\hline Outcome variable in Control (mean) & 0.605 & 0.605 & 0.605 & 0.329 & 0.701 & 0.298 & 0.696 & 0.613 & 0.595 \\
\hline H0: No treatment effects (p-value) & 0.094 & 0.051 & 0.053 & 0.575 & 0.074 & 0.288 & 0.017 & 0.122 & 0.380 \\
\hline Socio-demographic controls & & $\checkmark$ & $\checkmark$ & $\checkmark$ & $\checkmark$ & $\checkmark$ & $\checkmark$ & $\checkmark$ & $\checkmark$ \\
\hline Donation history controls & & $\checkmark$ & $\checkmark$ & $\checkmark$ & $\checkmark$ & $\checkmark$ & $\checkmark$ & $\checkmark$ & $\checkmark$ \\
\hline Days between donation and email & & $\checkmark$ & $\checkmark$ & $\checkmark$ & $\checkmark$ & $\checkmark$ & $\checkmark$ & $\checkmark$ & $\checkmark$ \\
\hline Study wave fixed effects & & & $\checkmark$ & $\checkmark$ & $\checkmark$ & $\checkmark$ & $\checkmark$ & $\checkmark$ & $\checkmark$ \\
\hline Observations & 8591 & 8581 & 8581 & 2236 & 6345 & 2011 & 6570 & 4641 & 3940 \\
\hline
\end{tabular}

${ }^{*} p<0.10 ;{ }^{* *} p<0.05 ;{ }^{* * *} p<0.01$

Notes: Standard errors in parentheses are clustered at the AVIS sub-branch level (121 clusters). Donation history controls include both blood and plasma donations in the twelve months prior to the blood donation that made donors eligible for this study. Days between donation and email range between 20 and 49, and represent a count of days elapsed between the donation that qualified the donor for the study and the day when the treatment email is sent to the donor. Socio-demographic controls include gender and age. Donors receive the treatment email between three and seven weeks after the blood donation that qualified them for the study. In columns (6) and (7) the sample is split at the median number of blood donations in the 12 months prior to the study. In column (8) we say that the email was sent Early if it was sent between three and five weeks after the donation, and Late if it was sent between five and seven weeks after the donation (this coincides with the median split of the sample by the number of days between donors' last blood donation and treatment email). For each regression we report p-values of an F-test of joint significance of the treatment effects (H0: Control = Feedback = Appointment $=$ Appointment $\&$ Feedback $)$.

We resort on a regression analysis to better assess the statistical significance of these findings and the interaction of positive feedback effects with the effects of inviting donors to schedule an early appointment. Table 2 reports the results from ordinary least square regressions. These results confirm the effect size of Feedback effects. In our preferred specification, that includes past donation behavior to improve the efficiency of our estimates, and accounts for the number of days elapsed between the latest blood 
donation and treatment email as well as for wave specific fixed effects, the treatment effect of Feedback is highly significant ( $\mathrm{p}$-value $=0.008$ ). The effect size is robust to the inclusion of various sets of controls (columns (1) to (3)). Moreover, the qualitative results are very similar if we use an negative binomial regression model for count data (table A2), or if we study the extensive margin of participation in the donation over the study period as the outcome of interest (table A3).

We also investigate heterogeneous treatment effects, by repeating the analysis after splitting the sample by gender, number of past blood donations, and number of days elapsed between the donation and the feedback. Qualitatively, the negative Feedback effect is relatively homogeneous across genders (columns (3) and (4)). The median number of blood donations before the donation that got donors eligible to take part in the study is 1 for both genders. Donors that have made at least one blood donation in the 12 months prior to the study are more likely to slow down donations when they receive a positive feedback on the impact of their actions (columns (5) and (6)). The third set of heterogeneity analyses is a test of the hypothesis from Conway and Peetz (2012) that reminders of more recent behavior is more likely to lead to morally compensatory outcomes. Consistently with this hypothesis, our data suggests that the negative feedback effects are driven by the behavior of donors who receive the treatment email between three and five weeks after their blood donation (Early, column (8)).

We also find that asking donors to sign up for an appointment, does not significantly affect donations, if anything the effect is negative. Other studies find that sending either text message or email invitations typically report positive effects (e.g. Sun et al. (2016)). However, one important difference with other studies in the literature is that they typically approach donors who are currently eligible to donate, whereas we send emails to donors when they have recently donated and will not be eligible to donate blood again for several months.

Interestingly, when combined, Feedback and Appointment display positive complementarities, indicating that bundling positive feedback with an explicit request to donate can improve the effectiveness of the positive feedback. However, in this setting, such complementarities are not strong enough to sufficiently offset the negative Feed- 
back effects.

Importantly, we can also assess whether the negative Feedback effect is due to a substitution with other types of donations. Blood and plasma constitute the vast majority of donations, and substitution of one type of donation with the other can in principle be beneficial for the collection system as a whole. We estimate the treatment effects of the experimental communications on plasma donations - the second most common type of donations among AVIS Toscana blood donors. The results of the regression analyses, reported in Table A1, rule out that the negative Feedback effect is attenuated by substitution with other types of donations. The estimated treatment effect of Feedback on plasma donations is a precise zero across multiple specifications with different control variables. An F-test of joint significance fails to reject the null hypothesis that treatment communications had no affect on plasma donations.

\section{Conclusions}

This study finds that the short term effects of providing positive feedback to the volunteer about the positive impact of her prosocial actions can be negative, large, and economically significant. These results are not encouraging for blood collection systems that employ similar approaches, informing donors of the impact of their donations as soon as these are utilized, and have implications for a broad set of collection systems that seek to engage the repeated voluntary provision of private contributions.

In Table 3, we summarize the closely related studies on the effect of providing donors with information on the utilization of their last donation. In all these studies, such information is provided to donors via text message, but otherwise the content of the message is fairly comparable. The only two studies that employ experimental methods show either null (Fosgaard et al., 2019) or small positive treatment effects (Moussaoui et al., 2019). Differences in the cultural context, in the timing at which information is sent to donors, and in the means of communication can make it hard to pin down exactly why results in our study are so qualitatively different. However, a noticeable element that separates these study from ours, is the lack of a clean control group of donors that receive a communication from the blood collection agency with- 
out the utilization information. Such control treatment is important: it helps our study cleanly identify the effect of information while holding constant attention towards the need for blood in society, and can explain the difference in results. ${ }^{7}$ However, more research is needed to systematically determine empirically when positive utilization feedback backfires.

Table 3: Existing Studies on the Effects of Utilization Feedback on Blood Donations Article Brief description

Gemelli et al. (2017)

Whitney and Hall (2010)

Fosgaard et al. (2019)

Moussaoui et al. (2019)
Matched cohort design provides quasi-experimental evidence that a text message informing Australian donors of utilization of their donation increases the probability of returning to give blood within 6 and 12 months by 5.4 p.p. $(p<0.01)$ and 7.2 p.p. $(p<0.01)$, respectively.

7 years of retrospective data show that American blood donors who pick up the phone with the blood bank and receive information about where their blood was used are more likely to perceive that their donation is important and are 2.2 p.p. $(p<0.01)$ more likely to donate again.

Field experiment randomizes whether Danish donors receive a text message informing of the utilization of their last donation. In the following three months, blood donations decrease by 0.2 p.p. $(p=0.554)$ and plasma donations increase by 8.2 p.p $(p<0.01)$.

Field experiment randomizes whether Swedish donors receive a thank you text message with vague information on the donation being ready for being used. Six to ten months after the text message, the probability that donors return to give blood increases by 1.8 p.p. $(p=0.025)$.

Given the increasing popularity of the tool in the context of blood donations and the available evidence, we were genuinely surprised by these effects. The results appear consistent with theories in which prosocial behavior is driven by an individual desire to maintain the self-concept of being a prosocial person. In these theories people act prosocial to remind themselves the altruistic person that they are and aspire to be. Need for such reminder is alleviated when a positive feedback serves as a reminder of the recent prosocial action. Much of the evidence for these theories comes from

\footnotetext{
${ }^{7}$ Also at a theoretical level, Bénabou and Tirole (2011) draw a distinction between information interventions that priming people about their own identity and can lead to moral consistency (more donations), from information affecting fuzzy memory of one's own altruism type that can lead to moral licensing (less donations).
} 
experiments in the laboratory (e.g. Monin and Miller (2001)). While this study is not a definitive test of the theory, it concurs with a few recent field studies (Tiefenbeck et al., 2013; Hofmann et al., 2014) to provide much needed early evidence consistent with the mechanism from a large sample in an important natural settings (Mullen and Monin, 2016).

This study highlights the importance of rigorous impact evaluations of policies that eventually get implemented at scale. While we show that objective information about utilization of a donation can backfire, further research might identify synergies with additional contents, such as appeals or emotional material, that might make similar policies beneficial for the collection. We already make some progress in this respect by showing positive synergies between utilization information and explicit requests to donate. Identifying more of such synergies will be especially beneficial to support the work of charities and NGOs that routinely give utilization feedback to their donors to prove themselves accountable.

While the short-term effects of positive feedback on the impact of donations can be negative, in the longer term, we can imagine that providing positive feedback could prove beneficial to a collection system if the policy is successful at improving retention of donors that are satisfied of their relationship with the organization. These are important inter-temporal trade-offs for collection systems of charitable contributions to balance. More research will be necessary to determine the longer term effects of these types of interventions and to be able to better support policy design.

\section{References}

Bénabou, Roland and Jean Tirole, "Identity, morals, and taboos: Beliefs as assets," The Quarterly Journal of Economics, 2011, 126 (2), 805-855.

_, Armin Falk, and Jean Tirole, "Narratives, imperatives, and moral reasoning," Technical Report, National Bureau of Economic Research 2018.

Bruhin, Adrian, Lorenz Goette, Simon Haenni, and Lingqing Jiang, "Spillovers of Prosocial Motivation: Evidence from an Intervention Study on Blood Donors," Journal of Health Economics, 2020, 70, 102244. 
Bryan, Christopher J, Gregory M Walton, Todd Rogers, and Carol S Dweck, "Motivating voter turnout by invoking the self," Proceedings of the National Academy of Sciences, 2011, 108 (31), 12653-12656.

Chaudhry, Shereen J and George Loewenstein, "Thanking, apologizing, bragging, and blaming: Responsibility exchange theory and the currency of communication.," Psychological review, 2019, 126 (3), 313.

Conway, Paul and Johanna Peetz, "When does feeling moral actually make you a better person? Conceptual abstraction moderates whether past moral deeds motivate consistency or compensatory behavior," Personality and Social Psychology Bulletin, 2012, 38 (7), 907-919.

Fosgaard, Toke, Lars Hansen, Catrine Jacobsen, Erik Sørensen, Merle Romose, and Henrik Ullum, "Can text messages save lives? A field experiment on blood donor motivation," Transfusion, 2019.

Gemelli, Carley, Alison Carver, Alana Garn, Stephen Wright, and Tanya Davison, "Evaluation of the impact of a personalized postdonation short messaging service on the retention of whole blood donors," Transfusion, 2017, 58.

Gerber, Alan S, Donald P Green, and Christopher W Larimer, "Social pressure and voter turnout: Evidence from a large-scale field experiment," American political Science review, 2008, 102 (1), 33-48.

Harrison, Glenn W and John A List, “Field experiments," Journal of Economic literature, 2004, 42 (4), 1009-1055.

Hofmann, Wilhelm, Daniel C Wisneski, Mark J Brandt, and Linda J Skitka, “Morality in everyday life," Science, 2014, 345 (6202), 1340-1343.

Huck, Steffen and Imran Rasul, "Transactions costs in charitable giving: evidence from two field experiments," The BE Journal of Economic Analysis E Policy, 2010, 10 (1).

Lacetera, Nicola and Mario Macis, "Social image concerns and prosocial behavior: Field evidence from a nonlinear incentive scheme," Journal of Economic Behavior $\mathcal{E}$ Organization, 2010, 76 (2), 225-237.

Monin, Benoit and Dale T Miller, "Moral credentials and the expression of prejudice.," Journal of personality and social psychology, 2001, 81 (1), 33. 
Moussaoui, Lisa S, Joëlle Herren-Vichet, Serena Baldelli, Sophie Waldvogel, and Olivier Desrichard, "Examining if Sending Text Messages to Thank Blood Donors for Saving Lives Is a "Great Idea"? Evidence from a Randomized Field Experiment," Journal of Nonprofit \& Public Sector Marketing, 2019, 31 (5), 486-506.

Mullen, Elizabeth and Benoît Monin, "Consistency versus licensing effects of past moral behavior," Annual review of psychology, 2016, 67, 363-385.

Panagopoulos, Costas, "Thank you for voting: Gratitude expression and voter mobilization," The Journal of Politics, 2011, 73 (3), 707-717.

Sachdeva, Sonya, Rumen Iliev, and Douglas L Medin, "Sinning saints and saintly sinners: The paradox of moral self-regulation," Psychological science, 2009, 20 (4), $523-528$.

Sonntag, Axel and Daniel John Zizzo, "On reminder effects, drop-outs and dominance: Evidence from an online experiment on charitable giving," PloS one, 2015, 10 (8), e0134705.

Sun, Tianshu, Susan Feng Lu, and Ginger Zhe Jin, "Solving shortage in a priceless market: Insights from blood donation," Journal of Health Economics, 2016, 48, 149165.

Tiefenbeck, Verena, Thorsten Staake, Kurt Roth, and Olga Sachs, "For better or for worse? Empirical evidence of moral licensing in a behavioral energy conservation campaign," Energy Policy, 2013, 57, 160-171.

Whitney, J. Garrett and Robert F. Hall, "Using an integrated automated system to optimize retention and increase frequency of blood donations," Transfusion, 2010. 


\section{A. Additional Figures and Tables}

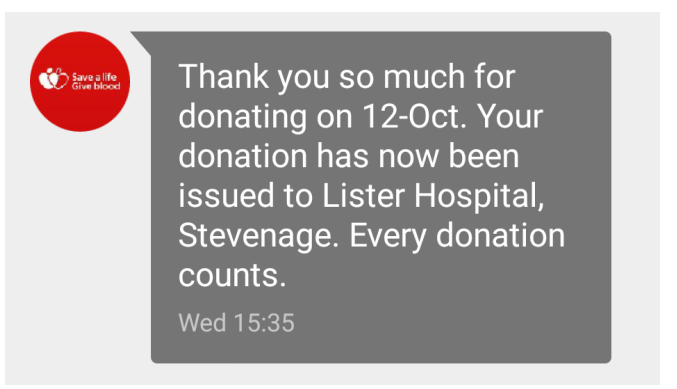

Figure A1: Example of Feedback from the UK National Health Service

Table A1: Ordinary Least Squares Regression Treatment Effects

\begin{tabular}{|c|c|c|c|}
\hline & \multicolumn{3}{|c|}{ Plasma donations over study period } \\
\hline & $(1)$ & $(2)$ & (3) \\
\hline & \multicolumn{3}{|c|}{ Baseline: Control group } \\
\hline \multirow[t]{2}{*}{ Feedback } & -0.014 & 0.001 & 0.001 \\
\hline & $(0.020)$ & $(0.016)$ & $(0.016)$ \\
\hline \multirow[t]{2}{*}{ Appointment } & $-0.028^{*}$ & -0.008 & -0.008 \\
\hline & $(0.016)$ & $(0.011)$ & $(0.011)$ \\
\hline \multirow{2}{*}{ Feedback $\times$ Appointment } & 0.022 & -0.005 & -0.005 \\
\hline & $(0.026)$ & $(0.019)$ & $(0.019)$ \\
\hline Average plasma donations over study period in Control & 0.157 & 0.157 & 0.157 \\
\hline H0: Control $=$ Feedback $=$ Appointment $=$ Appointment $\mathcal{E}$ Feedback $(\mathrm{p}$-value $)$ & 0.356 & 0.731 & 0.736 \\
\hline Socio-demographic controls & & $\checkmark$ & $\checkmark$ \\
\hline Donation history controls & & $\checkmark$ & $\checkmark$ \\
\hline Days between donation and email & & $\checkmark$ & $\checkmark$ \\
\hline Study wave fixed effects & & & $\checkmark$ \\
\hline Observations & 8591 & 8581 & 8581 \\
\hline
\end{tabular}

${ }^{*} p<0.10 ;{ }^{* *} p<0.05 ;{ }^{* * *} p<0.01$

Notes: Standard errors in parentheses are clustered at the AVIS sub-branch level (121 clusters). Donation history controls include both blood and plasma donations in the twelve months prior to the blood donation that made donors eligible for this study. Days between donation and email range between 20 and 49, and represent a count of days elapsed between the donation that qualified the donor for the study and the day when the treatment email is sent to the donor. Socio-demographic controls include gender and age. Donors receive the treatment email between three and seven weeks after the blood donation that qualified them for the study. In columns (2) and (3) we control for the number of days between last blood donation and treatment email. 
Table A2: Negative Binomial Regressions

\begin{tabular}{|c|c|c|c|c|c|c|c|c|c|}
\hline & \multicolumn{9}{|c|}{ Blood donations over study period } \\
\hline & \multicolumn{3}{|c|}{ Study sample } & \multicolumn{2}{|c|}{ by gender } & \multicolumn{2}{|c|}{ by past donations } & \multicolumn{2}{|c|}{ by timing email sent } \\
\hline & \multirow[b]{2}{*}{ (1) } & \multirow[b]{2}{*}{$(2)$} & \multirow[b]{2}{*}{ (3) } & \multirow{2}{*}{$\begin{array}{c}\text { Female } \\
\text { (4) }\end{array}$} & \multirow{2}{*}{$\begin{array}{c}\text { Male } \\
\text { (5) }\end{array}$} & \multirow{2}{*}{$\begin{array}{c}\text { Zero } \\
(6)\end{array}$} & \multirow{2}{*}{$\begin{array}{c}\text { One + } \\
\text { (7) }\end{array}$} & \multirow{2}{*}{$\begin{array}{c}\text { Early } \\
\text { (8) }\end{array}$} & \multirow{2}{*}{$\begin{array}{l}\text { Late } \\
\text { (9) }\end{array}$} \\
\hline & & & & & & & & & \\
\hline & & & & Bas & ine: Contrc & group & & & \\
\hline \multirow[t]{2}{*}{ Feedback } & $-0.072^{* *}$ & $-0.075^{* * *}$ & $-0.075^{* * *}$ & -0.115 & $-0.069^{* * *}$ & -0.070 & $-0.074^{* * *}$ & $-0.098^{* *}$ & -0.048 \\
\hline & $(0.031)$ & $(0.026)$ & $(0.026)$ & $(0.107)$ & $(0.026)$ & $(0.109)$ & $(0.023)$ & $(0.039)$ & $(0.037)$ \\
\hline \multirow[t]{2}{*}{ Appointment } & -0.034 & -0.033 & -0.033 & -0.067 & -0.027 & 0.069 & -0.047 & -0.060 & -0.004 \\
\hline & $(0.038)$ & $(0.032)$ & $(0.032)$ & $(0.101)$ & $(0.027)$ & $(0.114)$ & $(0.029)$ & $(0.043)$ & $(0.045)$ \\
\hline \multirow[t]{2}{*}{ Feedback $\times$ Appointment } & $0.099^{* *}$ & $0.087^{* *}$ & $0.086^{* *}$ & 0.215 & $0.065^{*}$ & 0.090 & $0.084^{* *}$ & $0.117^{* *}$ & 0.051 \\
\hline & $(0.045)$ & $(0.042)$ & $(0.042)$ & $(0.152)$ & $(0.035)$ & $(0.155)$ & $(0.042)$ & $(0.052)$ & $(0.051)$ \\
\hline H0: No treatment effects ( $\mathrm{p}$-value) & 0.086 & 0.035 & 0.036 & 0.435 & 0.055 & 0.306 & 0.016 & 0.086 & 0.335 \\
\hline Socio-demographic controls & & $\checkmark$ & $\checkmark$ & $\checkmark$ & $\checkmark$ & $\checkmark$ & $\checkmark$ & $\checkmark$ & $\checkmark$ \\
\hline Donation history controls & & $\checkmark$ & $\checkmark$ & $\checkmark$ & $\checkmark$ & $\checkmark$ & $\checkmark$ & $\checkmark$ & $\checkmark$ \\
\hline Days between donation and email & & $\checkmark$ & $\checkmark$ & $\checkmark$ & $\checkmark$ & $\checkmark$ & $\checkmark$ & $\checkmark$ & $\checkmark$ \\
\hline Study wave fixed effects & & & $\checkmark$ & $\checkmark$ & $\checkmark$ & $\checkmark$ & $\checkmark$ & $\checkmark$ & $\checkmark$ \\
\hline Observations & 8591 & 8581 & 8581 & 2236 & 6345 & 2011 & 6570 & 4641 & 3940 \\
\hline
\end{tabular}

${ }^{*} p<0.10 ;{ }^{* *} p<0.05 ;{ }^{* * *} p<0.01$

Notes: Standard errors in parentheses are clustered at the AVIS sub-branch level (121 clusters). Donation history controls include both blood and plasma donations in the twelve months prior to the blood donation that made donors eligible for this study. Days between donation and email range between 20 and 49, and represent a count of days elapsed between the donation that qualified the donor for the study and the day when the treatment email is sent to the donor. Socio-demographic controls include gender and age. Donors receive the treatment email between three and seven weeks after the blood donation that qualified them for the study. In columns (6) and (7) the sample is split at the median number of blood donations in the 12 months prior to the study. In column (8) we say that the email was sent Early if it was sent between three and five weeks after the donation, and Late if it was sent between five and seven weeks after the donation (this coincides with the median split of the sample by the number of days between donors' last blood donation and treatment email). For each regression we report p-values of an F-test of joint significance of the treatment effects (H0: Control $=$ Feedback = Appointment = Appointment $\mathcal{E}$ Feedback). 
Table A3: Logit Regressions, Odds Ratios

\begin{tabular}{|c|c|c|c|c|c|c|c|c|c|}
\hline & \multicolumn{9}{|c|}{ Donated blood over study period } \\
\hline & \multicolumn{3}{|c|}{ Study sample } & \multicolumn{2}{|c|}{ by gender } & \multicolumn{2}{|c|}{ by past donations } & \multicolumn{2}{|c|}{ by timing email sent } \\
\hline & \multirow[b]{2}{*}{ (1) } & \multirow[b]{2}{*}{$(2)$} & \multirow[b]{2}{*}{ (3) } & \multirow{2}{*}{$\begin{array}{c}\text { Female } \\
\text { (4) }\end{array}$} & \multirow{2}{*}{$\begin{array}{c}\text { Male } \\
\text { (5) }\end{array}$} & \multirow{2}{*}{$\begin{array}{c}\text { Zero } \\
(6)\end{array}$} & \multirow{2}{*}{$\begin{array}{c}\text { One + } \\
\text { (7) }\end{array}$} & \multirow{2}{*}{$\begin{array}{c}\text { Early } \\
\text { (8) }\end{array}$} & \multirow{2}{*}{$\begin{array}{l}\text { Late } \\
\text { (9) }\end{array}$} \\
\hline & & & & & & & & & \\
\hline & & & & Base & ine: Contrc & group & & & \\
\hline \multirow[t]{2}{*}{ Feedback } & $-0.167^{* *}$ & $-0.197^{* * *}$ & $-0.196^{* * *}$ & -0.171 & $-0.204^{* * *}$ & -0.089 & $-0.233^{* * *}$ & $-0.241^{* *}$ & -0.148 \\
\hline & $(0.068)$ & $(0.068)$ & $(0.069)$ & $(0.167)$ & $(0.078)$ & $(0.160)$ & $(0.070)$ & $(0.111)$ & $(0.091)$ \\
\hline \multirow[t]{2}{*}{ Appointment } & -0.074 & -0.075 & -0.074 & -0.095 & -0.067 & 0.100 & -0.128 & -0.150 & 0.009 \\
\hline & $(0.073)$ & $(0.079)$ & $(0.078)$ & $(0.156)$ & $(0.073)$ & $(0.165)$ & $(0.081)$ & $(0.109)$ & $(0.114)$ \\
\hline \multirow[t]{2}{*}{ Feedback $\times$ Appointment } & $0.236^{* *}$ & $0.241^{* *}$ & $0.238^{* *}$ & 0.332 & $0.206^{*}$ & 0.109 & $0.280^{* *}$ & $0.362^{* *}$ & 0.101 \\
\hline & $(0.103)$ & $(0.116)$ & $(0.115)$ & $(0.243)$ & $(0.110)$ & $(0.230)$ & $(0.125)$ & $(0.148)$ & $(0.137)$ \\
\hline H0: No treatment effects ( $\mathrm{p}$-value) & 0.054 & 0.028 & 0.029 & 0.477 & 0.075 & 0.351 & 0.009 & 0.099 & 0.206 \\
\hline Socio-demographic controls & & $\checkmark$ & $\checkmark$ & $\checkmark$ & $\checkmark$ & $\checkmark$ & $\checkmark$ & $\checkmark$ & $\checkmark$ \\
\hline Donation history controls & & $\checkmark$ & $\checkmark$ & $\checkmark$ & $\checkmark$ & $\checkmark$ & $\checkmark$ & $\checkmark$ & $\checkmark$ \\
\hline Days between donation and email & & $\checkmark$ & $\checkmark$ & $\checkmark$ & $\checkmark$ & $\checkmark$ & $\checkmark$ & $\checkmark$ & $\checkmark$ \\
\hline Study wave fixed effects & & & $\checkmark$ & $\checkmark$ & $\checkmark$ & $\checkmark$ & $\checkmark$ & $\checkmark$ & $\checkmark$ \\
\hline Observations & 8591 & 8581 & 8581 & 2236 & 6345 & 2011 & 6570 & 4641 & 3940 \\
\hline
\end{tabular}

${ }^{*} p<0.10 ;{ }^{* *} p<0.05 ;{ }^{* * *} p<0.01$

Notes: Standard errors in parentheses are clustered at the AVIS sub-branch level (121 clusters). Donation history controls include both blood and plasma donations in the twelve months prior to the blood donation that made donors eligible for this study. Days between donation and email range between 20 and 49, and represent a count of days elapsed between the donation that qualified the donor for the study and the day when the treatment email is sent to the donor. Socio-demographic controls include gender and age. Donors receive the treatment email between three and seven weeks after the blood donation that qualified them for the study. In columns (6) and (7) the sample is split at the median number of blood donations in the 12 months prior to the study. In column (8) we say that the email was sent Early if it was sent between three and five weeks after the donation, and Late if it was sent between five and seven weeks after the donation (this coincides with the median split of the sample by the number of days between donors' last blood donation and treatment email). For each regression we report p-values of an F-test of joint significance of the treatment effects (H0: Control $=$ Feedback = Appointment = Appointment $\mathcal{E}$ Feedback). 


\section{B. Original Contents of Email Communications}

\section{GVIS CRS}

Ciao Rodi,

Insieme al Centro Regionale Sangue stiamo lavorando per fornirti maggiori informazioni sull'esito delle tue donazioni.

Presto sarai in grado di consultare online, da un account personale riservato, l'esito dei test di routine successivo ad ogni donazione. Stiamo anche considerando diversi sistemi di informazione al donatore sull'utilizzo delle sue donazioni.

Se hai una richiesta, su informazioni che ti piacerebbe avere circa la tua donazione, scrivici all'indirizzo informazioni@avistoscana.it. Proveremo ad accontentare alcune delle richieste che riceveremo.

Un caro saluto,

Adelmo Agnollucci

Presidente AVIS Toscana

Simona Carli

Direttore Centro Regionale Sangue

Se vuoi essere aggiornato sulle nostre iniziative, storie di donatori, e ringraziamenti di chi senza donazioni non ce l'avrebbe fatta, segui Avis Se vuoi essere aggionato sulle

Figure A2: Control Treatment

\section{QVis $\triangle$ CRS}

Ciao Luciano,

Insieme al Centro Regionale Sangue stiamo lavorando per fornirti maggiori informazioni sull'esito delle tue donazioni.

Presto sarai in grado di consultare online, da un account personale riservato, l'esito dei test di routine successivo ad ogni donazione. Stiamo anche considerando diversi sistemi di informazione al donatore sull'utilizzo delle sue donazioni.

Se hai una richiesta, su informazioni che ti piacerebbe avere circa la tua donazione, scrivici all'indirizzo informazioni@avistoscana.it. Proveremo ad accontentare alcune delle richieste che riceveremo.

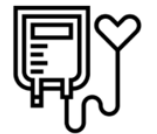

Nel frattempo, ci fa piacere poterti comunicare che la tua donazione del 5 Maggio 2018 è stata già utilizzata!

Un caro saluto,

Adelmo Agnollucci

Presidente AVIS Toscana

Simona Carli

Direttore Centro Regionale Sangue

Figure A3: Feedback Treatment 


\section{QVIS CRS}

Ciao Egon,

Insieme al Centro Regionale Sangue stiamo lavorando per fornirti maggiori informazioni sull'esito delle tue donazioni.

Presto sarai in grado di consultare online, da un account personale riservato, l'esito dei test di routine successivo ad ogni donazione. Stiamo anche considerando diversi sistemi di informazione al donatore sull'utilizzo delle sue donazioni.

Se hai una richiesta, su informazioni che ti piacerebbe avere circa la tua donazione, scrivici all'indirizzo informazioni@avistoscana.it. Proveremo ad accontentare alcune delle richieste che riceveremo.

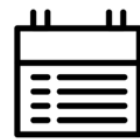

Come ben sai, c'è sempre bisogno di sangue e plasma.

Chiama gli amici di AVIS Pistoia (057 323765 ) per fissare un appuntamento pe la prossima donazione e torna presto a trovarci

Un caro saluto,

Adelmo Agnollucci

Presidente AVIS Toscana

Simona Carli

Direttore Centro Regionale Sangue

Se vuoi essere aggiornato sulle nostre iniziative, storie di donatori, e ringraziamenti di chi senza donazioni non ce l'avrebbe fatta, segui Avis Regionale Toscana su Facebook.

Figure A4: Appointment Treatment

\section{QVIS CRS}

Ciao Egon,

Insieme al Centro Regionale Sangue stiamo lavorando per fornirti maggiori informazioni sull'esito delle tue donazioni.

Presto sarai in grado di consultare online, da un account personale riservato, l'esito dei test di routine successivo ad ogni donazione. Stiamo anche considerando diversi sistemi di informazione al donatore sull'utilizzo delle sue donazioni.

Se hai una richiesta, su informazioni che ti piacerebbe avere circa la tua donazione, scrivici all'indirizzo informazioni@avistoscana.it. Proveremo ad accontentare alcune delle richieste che riceveremo.

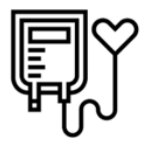

Nel frattempo, ci fa piacere poterti comunicare che la tua donazione del $\mathbf{9}$ Maggio 2018 è stata già utilizzata!

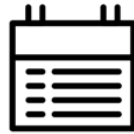

Come ben sai, c'è sempre bisogno di sangue e plasma.

Chiama gli amici di AVIS Pistoia (057 323765 ) per fissare un appuntamento per la prossima donazione e torna presto a trovarci!

Un caro saluto,

Adelmo Agnollucci

Presidente AVIS Toscana

Simona Carli

Direttore Centro Regionale Sangue

Se vuoi essere aggiornato sulle nostre iniziative, storie di donatori, e ringraziamenti di chi senza donazioni non ce l'avrebbe fatta, segui Avis Regionale Toscana su Facebook.

Figure A5: Appointment \& Feedback Treatment 